\title{
Study of Physical Properties of Zea mays in the Development of Seed Metering Unit
}

\author{
Ajay, A. ${ }^{1 *}$, Rami Reddy, K.V.S. ${ }^{2}$ and Ashok Kumar, A. ${ }^{3}$ \\ ${ }^{1}$ Department of Farm Machinery and Power Engineering, Acharya NG Ranga Agricultural University, Bapatla, A.P. India \\ ${ }^{2}$ Department of Farm Machinery and Power Engineering, Acharya NG Ranga Agricultural University, Bapatla, A.P. India \\ ${ }^{3}$ AICRP on FIM, Acharya NG Ranga Agricultural University, Bapatla, A.P. India
}

*Corresponding author: ajayarigela1997@gmail.com (ORCID ID: 0000-0002-3193-7731)

Paper No. 892

Received: $19-03-2021$

Revised: 22-05-2021

Accepted: 04-06-2021

\begin{abstract}
The physical properties of seeds are very important to optimize the design parameters of various agricultural equipment used in their production, handling, and storage processes. Determination and use of these properties are also essential for the development of optimum seed metering mechanism and also in the design of a hopper for a planter for precise sowing of seeds. Physical properties such as length, surface area, breadth, roundness, equivalent diameter, sphericity, angle of repose, and coefficient of friction were determined for the development of the seed metering unit. The physical properties of seeds were calculated initially. Three varieties of maize seed Rasi-3033, NMH-589, and KMH-2589. The mean values of seed length, width, thickness, sphericity, geometric mean diameter, surface area, bulk density, coefficient of static friction, angle of repose, and thousand kernel weight were $11.00 \mathrm{~mm}, 7.75 \mathrm{~mm}$, $4.58 \mathrm{~mm}, 0.65,7.09 \mathrm{~mm}, 158.14 \mathrm{~mm}^{2}, 746.4 \mathrm{~kg} \mathrm{~m}^{-3}, 0.60,28.17^{\circ}$ and $0.23 \mathrm{~kg}$, respectively. These properties were used in the development of efficient planter components to work effectively.
\end{abstract}

\section{HIGHLIGHTS}

( Physical properties are essential in the development of planter components.

0 The angle of repose is increased with increasing the moisture content of the seeds.

0 Bulk density is important to design the volume of the seed hopper for the seed planter.

Keywords: Maize, Sphericity, coefficient of friction, angle of repose, metering unit, roundness, and Bulk density

Maize (Zea mays L) is one of the most suitable crops and more extensive versatility under different agro-climatic conditions. Maize is the world's important cereal crop with the highest production and productivity next to rice and wheat. After rice and wheat, maize is the third most significant crop in India. A conventional method of cultivation and lack of precision planting methods are the factors affecting the maize yield. As a result, in order to minimize labor requirements and input costs, India needs precise and cost-effective for direct planting of maize. The development of a precise metering mechanism for sowing maize seed that could provide higher seed singulation and minimal seed missing in the field was required to solve this issue, and the analysis of engineering properties of maize seeds is essential for this development.

The seed metering mechanism is essential to any planter's efficiency. It has an effect on the planter's design and performance parameters (Singh et al. 2007). In the design of any planter, the physical properties of the seed are very important. Seed physical and mechanical properties not only influence planters and also different processing machines such as cleaners, graders, sorting machines, threshers, and transporting components in the processing of seed. Most physical properties

How to cite this article: Ajay, A., Rami Reddy, K.V.S. and Ashok Kumar, A. 2021. Study of Physical Properties of Zea mays in the Development of Seed Metering Unit. IJAEB, 14(2): 159-163. 
which influence the design of seed metering and other components of seed planter are size, shape, mass, angle of repose, coefficient of friction, bulk density, and aerodynamic properties (Mohsenin, 1970). Furthermore, the coefficient of friction of seeds on different surfaces influences the effect of seeds on the internal components of the planter. Size, shape, axial dimensions, roundness, and sphericity helps to determine the maximum size of the cell or cup in the seed plate, for the selection of the frame for planter weight is important, the bulk density and moisture content helps to know the interaction between the seed and the material used for the hopper of the planter, angle of repose helps to ensure free flow of seed in the hopper (Jayan and Kumar 2004). Therefore, before designing and fabricating the planter's components, it is essential to conduct experiments on the physical properties of the required seeds.

\section{MATERIALS AND METHODS}

Three varieties of maize were selected for the study Rasi-3033, NMH-589, and KMH-2589 from a local market. Size, sphericity, thousand kernel weight, geometric mean diameter, surface area, bulk density, and angle of repose were measured in a laboratory. These properties were used in the development of efficient planter components to work effectively.

\section{Size}

The seed size was determined by length (1), width (w), and thickness ( $t$ ). Maize seed size is an essential parameter in designing the cell size on the seed metering mechanism. Vernier caliper was used to measure the axial and lateral dimensions of the seeds. Ten seeds were randomly selected, measuring the dimensions. The mean values have been estimated, and this value was used to design the metering mechanism. It was calculated by using the formula specified by (Mohensin 1970). It is shown in Fig. 2.

$$
\begin{aligned}
& l=\frac{\sum_{i=1}^{10} l_{i}}{10}, m m \\
& w=\frac{\sum_{i=1}^{10} w_{i}}{10}, m m \\
& t=\frac{\sum_{i=1}^{10} t_{i}}{10}, m m
\end{aligned}
$$

Where $l=$ mean length of the seed, $m m w=$ mean width of seed, $m m t=$ mean thickness of seed, $\mathrm{mm}$

\section{Geometric mean diameter}

The geometric mean seed diameter was measured with seed dimensions. The geometric diameter was determined using the following relation.

Geometric mean diameter, $D_{g}=(1 \mathrm{w} \mathrm{t})^{1 / 3}, \mathrm{~mm}$
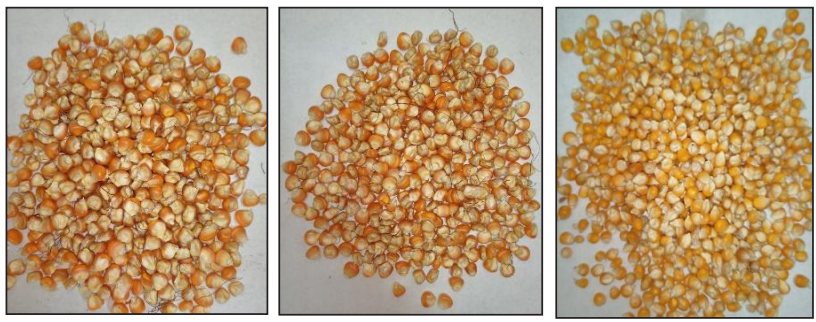

Fig. 1: Rasi-3033, NMH-539, KMH-2589 varieties of maize seeds

\section{Sphericity}

Sphericity is known as the ratio of the sphere's diameter having the same volume as that of the particle and diameter of the smallest circumscribing sphere, or the largest particle diameter generally. This parameter indicates the shape character of maize seeds relative to the same volume of a sphere. The dimensions of 10 maize seeds at random were measured using digital vernier caliper to calculate the seed sphericity.

Sphericity, $\varphi=\frac{\text { Volume of the particle }}{\text { Volume of the circumscribed sphere }}$

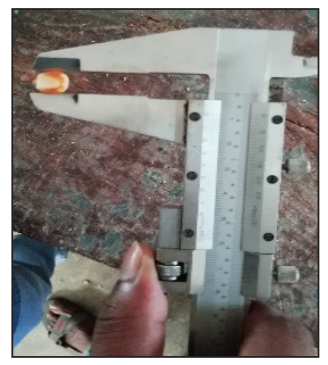

Fig. 2: Measuring of seed dimensions by using vernier calipers

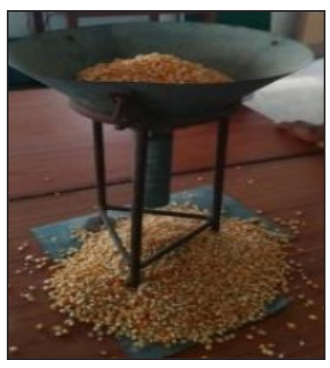

Fig. 3: Measurement of angle of repose

\section{Thousand kernel weight}

An electronic weighing balance with a precision of $0.01 \mathrm{~g}$ was used to determine the weight of thousand seeds. A sample of 100 seeds was randomly selected and weighed to determine the mean weight of 1000 
seeds. To minimize the errors, the procedure was replicated five times.

\section{Angle of repose}

Angle of repose is an important parameter that helps in the design of the hopper of the planter. A box with a circular base was mounted in the funnel, and three adjustable screws were used to hold the platform horizontally. It was filled with maize seeds. The seed gate on the underside of the funnel was removed so that a conical heap was formed on the surface. Heap height and diameter were measured. The angle of repose was calculated using the following equation. It is shown in Fig. 3.

$$
\text { Angle of repose, } \theta=\tan ^{-1}\left(\frac{2 h}{d}\right)
$$

Where $h=$ height of the cone formed, $\mathrm{cm} d=$ diameter of the base of cone-formed, $\mathrm{cm}$

\section{Bulk density}

A measuring cylinder was used to calculate the bulk density. A 1000 cc capacity measuring cylinder was taken, and its weight was taken as $W_{1}$. The seeds were filled up to the $1000 \mathrm{cc}$ limit, and the cylinder was gently tapped, and weight was taking as $w_{2}$. The difference between $w_{2}$ and $W_{1}$ was considered seed weight. Five replications were taken to minimize the error. Bulk density was calculated by using the following formula.

$$
\text { Bulk density }\left(\mathrm{kg} \mathrm{m}^{-3}\right)=\frac{\text { Weight of seed, } \mathrm{kg}}{\text { Volume of cylinder, } \mathrm{cm}^{3}}
$$

\section{Porosity}

The porosity is the fraction of the space in the bulk seeds which is not occupied by the seeds (Mohensenin, 1986). The porosity of the samples was computed from the bulk and true densities using the following equation:

$$
\text { Porosity, } \varepsilon\left(1-\frac{\rho_{b}}{\rho_{t}}\right) \times 100
$$

Where, $\rho_{b}=$ bulk density, $\mathrm{kg} \mathrm{m}^{-3} \rho_{t}=$ true density, $\mathrm{kg} \mathrm{m} \mathrm{m}^{-3}$

\section{Surface area}

The total area covered around the seed is the surface area of the maize seed. It can be given by the following formula:

$$
\text { Surface area, } S=\pi D_{g}^{2}
$$

Where $D_{g}=$ geometric mean diameter, $\mathrm{mm}$

\section{Coefficient of static friction}

Coefficient of static friction can be expressed in terms of the degree of the seed resistance to flow on a given surface. It is an important property to determine the angle at which the hopper development has to be done so that the constant flow of the seeds from the hopper to the seedbox is achieved. Coefficient of static friction is measured using the inclined plane method. The seeds were filled in a square box having dimensions $60 \times 65$ $\times 65 \mathrm{~mm}$, and the box was placed on the surface to measure the static coefficient of friction, then the surface on which the box lies was raised with a screw device. The angle at which the box begins to slide was noted from the graduated scale on the apparatus. The coefficient of static friction was calculated as the tangent of an angle of inclination and is given by the following equation. It is shown in Fig. 4.

Coefficient of static friction, $\mu=\tan \alpha$

Where $\alpha=$ angle of inclination.
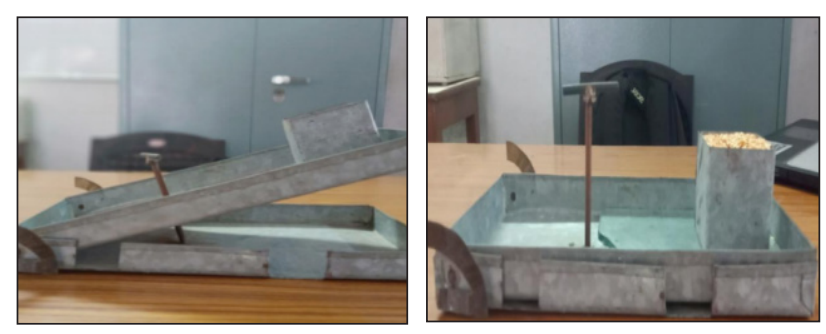

Fig. 4: Measurement of coefficient of static friction

\section{RESULTS AND DISCUSSION}

\section{Size and Shape}

Major, intermediate and minor dimensions of the three maize verities are Rasi-3033, NMH-589, and $\mathrm{KMH}-2589$ are given in the table 1. For Rasi-3033 the seed length varied from $10.42-11.60 \mathrm{~mm}$, 
Table 1: Geometrical properties of selected varieties of maize seeds

\begin{tabular}{lllllll}
\hline Seed Varieties & Value & Length, $\mathbf{m m}$ & Width, $\mathbf{m m}$ & $\begin{array}{l}\text { Thickness, } \\
\mathbf{m m}\end{array}$ & $\begin{array}{l}\text { Geometric mean } \\
\text { diameter, } \mathbf{m m}\end{array}$ & Sphericity \\
\hline \multirow{5}{*}{ Rasi-3033 } & Minimum & 10.50 & 7.11 & 4.204 & 6.90 & 0.63 \\
& Maximum & 11.49 & 8.63 & 4.53 & 7.40 & 0.69 \\
& Mean & 11.00 & 7.75 & 4.58 & 7.09 & 0.65 \\
& SD & 0.39 & 0.50 & 0.28 & 0.17 & 0.02 \\
\hline \multirow{5}{*}{ NMH-589 } & Minimum & 9.87 & 7.92 & 4.53 & 7.40 & 0.69 \\
& Maximum & 10.59 & 8.99 & 5.32 & 7.95 & 0.76 \\
& Mean & 10.24 & 8.55 & 5.05 & 7.61 & 0.73 \\
KMH-2589 & SD & 0.25 & 0.38 & 0.22 & 0.18 & 0.02 \\
& Minimum & 7.99 & 6.29 & 4.19 & 5.91 & 0.71 \\
& Maximum & 8.99 & 7.22 & 5.32 & 6.79 & 0.83 \\
& Mean & 8.34 & 6.92 & 4.91 & 6.56 & 0.78 \\
\hline
\end{tabular}

Table 2: Some properties of selected varieties of maize seeds

\begin{tabular}{lllll}
\hline Seed Variety & $\begin{array}{l}\text { Angle of repose } \\
\text { (degree) }\end{array}$ & $\begin{array}{l}\text { Bulk density } \\
\left(\mathbf{k g ~ m}^{-3}\right)\end{array}$ & $\begin{array}{l}\text { Thousand kernel weight } \\
\mathbf{( g )}\end{array}$ & Coefficient of static friction \\
\hline Rasi-3033 & 29.49 & 746.40 & 260.21 & 0.60 \\
NMH-589 & 30.20 & 721.50 & 210.20 & 0.59 \\
KMH-2589 & 29.54 & 709.99 & 240.00 & 0.55 \\
\hline
\end{tabular}

intermediate dimensions are in the range of 7.11 $8.63 \mathrm{~mm}$, and the minor dimensions are 4.13- 4.94, having mean values of $11.00,7.75$, and $4.58 \mathrm{~mm}$ respectively. NMH-589 seed having the length, width, thickness is varied from $9.87-10.59 \mathrm{~mm}, 7.92$ $-8.99 \mathrm{~mm}$, and $4.91-5.32 \mathrm{~mm}$ respectively. $\mathrm{KMH}-$ 2589 seed variety having a length range from 7.97 $-8.99 \mathrm{~mm}$, width varies from $6.29-7.01 \mathrm{~mm}$, and thickness is about $4.22-5.55 \mathrm{~mm}$. The geometric mean diameter of all three varieties is 5.91- 7.061. the sphericity of all the seed varieties $0.65-0.78$. These observations show that the maize seed was oblong in shape.

\section{Thousand kernel weight}

Table 2 shows the test weights of the various maize seed varieties under investigation. Due to differences in maize seed size, there was variation in the test weight of different varieties. Rasi-3033, NMH-589, and KMH-2589 maize seeds have an average hundred grain weight of 26.99, 21.02 and $24.0 \mathrm{~g}$, respectively. As a result, the test weight varies very little. The seed rate per hectare is estimated using the thousand kernel weight of maize seeds as a main factor. The average weight was between 210 to $260 \mathrm{~g}$.

\section{Angle of repose}

The average values of angle of repose for three maize seed varieties were $29.49^{\circ}, 30.20^{\circ}$, and $29.54^{\circ}$. Angle of repose is used to determine the slope of the seed hopper sidewalls to facilitate the free flow of maize seeds.

\section{Bulk density}

The bulk density of all four varieties were shown in table 2. The bulk density of all three maize seed varieties ranged from 710 to $746.4 \mathrm{~kg} \mathrm{~m}^{-3}$. The variation in bulk density between the varieties was due to the difference in the individual weight of individual grain and particle distribution i.e, variation in the size among the variety.

\section{Coefficient of Static Friction}

The values for the coefficient of static friction for Rasi-3033, NMH-589 and KMH-2589 maize seed varieties found $0.60,0.59$ and 0.55 respectively. 


\section{CONCLUSION}

The study on the physical properties of three different maize seed varieties led to the following conclusions. The shape and size of the cell on the metering plate will be affected by the shape of the seeds mostly. From the results, the length, width, and thickness are varied from 10.50 - 11.49, 7.118.63 , and $4.20-4.53 \mathrm{~mm}$ respectively. The shape of the maize seeds is in an oblong shape, so the cell shape on the metering plate should be in an oblong shape, and it easy to hold the seed within it. Angle of repose of seeds up to $30.20^{\circ}$, so that the sidewalls of the hopper should be not less than the angle of repose of the seeds. Frictional properties are used in the design of hoppers.

\section{REFERENCES}

Baryeh, E.A. 2002. Physical properties of millet. J. Food Engg., 51: 39-46.

Deshpande, S.D., Bal, S. and Ojha, T.P. 1993. Physical properties of soybean seeds. J. Agri. Engg. Res., 56: 89-92.

Inderpal, S.B., Anoop, K.D., Rohinish, K. and Anand, G. 2017. Studies on Physical Properties of Maize (Zea mays L.) Seeds. Int. J. Curr. Microbiol. Appl. Sci., 6(10): 963-970.
Jayan, P.R. and Kumar, V.J.F. 2006. Planter design in relation to the physical properties of seeds. J. Trop. Agric., 42(1-2): 69-71.

Manoharan, M. 2018. A comprehensive study on physical properties of black gram and green gram for developing a planter. Int. J. Agric. Sci. Res., 8(6): 71-74.

Matouk, A., El-kholy, M., Tharwat, A., El-far, S. and Sara El-serey. 2018. Dertermination of physical properties of some legume crops. J. Soil Sci. Agric. Engg., 9(11): 683-691.

Mohsenin, N.N. 1970. Physical properties of plant and Animal Materials. Gordon and Breach Science Publishers, New York, pp. 51-83.

Sangamithra, A., Gabriela, J.S., Prema, R.S., Nandini, K., Kannan, K., Sasikala, S. and Suganya, P. 2016. Moisture dependent physical properties of maize kernels. Int. Food Res. J., 23(1): 109.

Suwanpayak, N., Wijitpap, T., Srisongkram, P. and Nokkou, R. 2016 Some physical and mechanical properties of upland rise seed. Int. J. Adv. Agric. Env. Engg., 3(2): 336-338.

Yenge, G.B., Kad, V.P. and Nalawade, S.M. 2018. Physical properties of maize (Zea mays L.) grain. J. Krishi Vigyan, 7: $125-128$. 
